\title{
LA OBSERVACIÓN CASUAL DE LAS TRANSFORMACIONES SOCIO-MEDIÁTICAS DESDE LA MIRADA DE LA CÁMARA: PRIMEROS INDICIOS EN MONTREAL Y MÉXICO DF EN LOS AÑOS NOVENTA
}

CASUAL OBSERVATION OF SOCIO-MEDIATIC TRANSFORMATIONS FROM DE CAMERA PERSPECTIVE: FIRST EVIDECENCES IN MONTREAL AND MEXICO D.F. IN THE 1990S

Nicolás Lorite García

nicolas.lorite@uab.cat

Professor titular do Departamento de Publicidade e Relações Públicas e Comunicação Audiovisual. Diretor do Migracon (Observatório e Grupo de Investigação de Migração e Comunicação) da Universidade Autonôma de Barcelona (UAB).

\section{RESUMO}

Este artigo descreve as primeiras evidências de um método próprio de pesquisa audiovisual (aplicada) obtidas a partir de observação casual (mas não rasa) mediatizada por câmera no Grupo de Pesquisa sobre Indústrias Culturais e Informatização Social da Universidade de Quebec, Canadá, e no Instituto Tecnológico e de Estudos Superiores de Monterrey, México, em 1999.

Palavras-chave: Audiovisual. Midiatização. Observação casual.

\begin{abstract}
In this paper I describe the first evidences of an own (applied) audio-visual research method obtained after a camera mediatised casual (though not shallow) observation in the GRICIS-UQAM (Montreal) during 1996 and 1997 and in the TEC Monterrey (Mexico DF) in 1999.
\end{abstract}

Keywords: Audiovisual. Mediatisation. Casual observation.

\section{RESUMEN}

En este artículo describo los primeros indicios de un método propio de investigación audiovisual (aplicada), obtenidos desde la observación casual (que no es la casual observación), mediatizada por la cámara, durante mis estancias en Montreal, en el GRICIS-UQAM, en los años 1996 y 1997 y en el TEC de Monterrey de México DF en el año 1999.

Palabras clave: Audiovisual. Mediatización. Observación casual. 


\section{INTRODUCCIÓN}

En este artículo voy a describir en primera persona (normalmente intento redactar mis textos en tercera persona porque me siguen pareciendo más científicos a pesar de lo relativo que sigo considerando que es el quehacer científico) y a modo de historia de vida personal, los primeros indicios (GINZBURG, 1979, 1994) de un método propio de investigación audiovisual (aplicada), desde la mirada audiovisual o mi peculiar manera de ver la realidad mediatizada por la cámara. Estas primeras experimentaciones gráfico-textuales, que acabo sintetizando de acuerdo a la gramática textual, aunque estén codificadas con el lenguaje audiovisual, las llevo a cabo durante la década de los noventa durante mi estancia en el GRICIS (Groupe de Recherche sur les Industries Culturelles et l'Informatisation Social de la Universidad de Quebec a Montreal, Canadá) en los años 1996 y 1997 y en el Tec de Monterrey de México DF en el 1999.

Fui a un centro pionero de investigación como el GRICIS dispuesto a diseñar un marco de "Parámetros para el análisis de la informatización social en España", becado por la Secretaría de Estado de Universidades e Investigación, pero acabé derivando hacia el estudio de las transformaciones socio-mediáticas (TSM), producidas por las nuevas (eran denominadas nuevas aún) tecnologías de la información y la comunicación (NTIC). Llegué con una propuesta formal, estructuralista, muy positivista y academicista para diseñar mis parámetros, pero desarrollé a la vez otra más metafórica, poética y heurística, influenciado por autores como Feyerabend (1981) y sus anárquicas aportaciones contra el método, y McLuhan y Fiore (1968) y Foucault (1981) y sus derivaciones gráficas, fotográficas y pictóricas. Salí indemne de este doble proceso investigador y en vez de acabar con los problemas de doble personalidad logré ampliar considerablemente los registros de mi conocimiento social, desde el audiovisual y de la sincronía socio-mediática de ambos. Defendía el método científico, pero lo rompía a la vez. Puedo confesar ahora, al cabo de los años y desde la tranquilidad que da tener mi carrera académica resuelta y no verme en la necesidad de justificarlo todo de manera racional, que disfruté más con la perspectiva rupturista que con la formal. La ruptura me permitió adentrarme en el gratificante juego epistemológico de "atrapar moléculas del aire en movimiento", desde una metodología como la observación casual (que no es casual observación), para viajar en el tren de las transformaciones socio-mediáticas y no verlo pasar desde la estación. Ambas tendencias investigadoras se van fusionando y nutren la tercera perspectiva investigadora que también inicio por entonces: la del tratamiento mediático de la inmigración y la diversidad sociocultural en los medios de comunicación (principalmente prensa, radio, televisión e Internet), analizado desde la producción, emisión, recepción y dinamización intercultural de los mensajes. Para esta tercera vía parto de hipótesis que debo refutar para otorgarle a mis resultados el oportuno rigor científico, extrapolable y objetivo, pero teniendo en cuenta las transformaciones socio-mediáticas desde la mirada de la cámara. Por eso acabo defendiendo como científico el doble resultado que deriva hacia la publicación textual pero también hacia la producción audiovisual. Los resultados de una investigación audiovisual pueden y deben ir destinados a ser difundidos de diferentes maneras textuales y audiovisuales, todas ellas científicas. Nunca el audiovisual ha de quedarse relegado al texto y menos si se trata de una investigación que analiza el audiovisual.

A todo este complejo proceso investigador iba incorporando las propuestas de investigación-acción que estaba defendiendo desde que me incorporo a la investigación universitaria en los 80 , consistentes en vincularla a la sociedad y sus organizaciones, y en particular a producir el discurso o mensaje adecuado desde las mismas rutinas productivas de los medios de comunicación e información con sus procesos recepción y dinamización social e intercultural. Nunca me ha gustado investigar la realidad socio-mediática para dejar dormir los resultados en las bibliotecas o despachos universitarios o hacerlos circular tan solo por los 
circuitos "autárquicos" y elitistas de la Academia. Siempre le he buscado a la investigación una aplicación práctica, una conexión con la realidad. Por eso mi estancia en Montreal y México D.F., en los 90, la destino a proponer la mejor manera de investigar las transformaciones socio-mediáticas, desde la misma transformación, y a derivar dicho conocimiento a una epistemología del audiovisual, destinada a mediatizar de manera inclusiva la sociedad desde la misma sociedad, nunca desde las conclusiones textuales de un informe académico, sino desde un conocimiento que permita reproducir imaginarios reales y no estereotipados, discursos audiovisuales y modelos de representación audio y/o visual que susciten procesos de dinamización intercultural activos e integradores desde el consumo diverso de los mensajes de los medios de comunicación e información. Me anima a seguir por este camino lo que expresó Jesús Ibáñez (1998, p. 7), uno de los investigadores sociales al que no ceso de acudir con el paso de los años:

\footnotetext{
Uno, como el protagonista de Morgan, caso clínico, ha tenido muchas veces la impresión de vivir en una isla de sensatez rodeado de un mar de locura. Pero nunca la impresión ha sido tan vívida como cuando se ha visto rodeado de sus colegas los investigadores sociales. Especialmente, los que a sí mismos se llaman -con mayúsculas- científicos. Hacen lo que hacen sin pensar en lo que hacen, aplican sus rutinas sin saber por qué ni para qué. Rutinas que han tomado prestadas de una ciencia que se construyó en otro tiempo -hace 300 años- para otros fines -el estudio de los fenómenos físicos -. ¿Será que uno es muy listo y ellos muy tontos? Es una hipótesis muy improbable. Todo parece indicar que los listos son ellos: pues el pago -en dinero, en prestigio o en amor- les llueve a cántaros. Mientras que uno, y los que son como uno, permanece aislado en la isla.
}

\section{ATRAPAR LAS MOLÉCULAS DEL AIRE EN MOVIMIENTO}

A mediados de la década de los noventa se estaba dando una fuerte expansión de las nuevas (denominadas aún así, aunque ya no eran tan nuevas) tecnologías de la información y la comunicación (NTIC) al servicio de unas autopistas de información y comunicación y una red de redes como Internet que empezaban a mostrarse como el recurso comunicativo global que es actualmente (ECHEVARRIA, 1994; NEGROPONTE, 1995). Metrópolis como Montreal, ubicada en esa área geográfico-económica, de Canadá y Estados Unidos, de máxima influencia mundial, de la que surge y se prueba cualquier nuevo avance informático y tecnológico y que llevaban desde los 80 investigando los procesos comunicativos generados por la informatización social (SANTERRE, 1990, p. $71 ; 1994)$, era un lugar adecuado para conocer estos procesos socio-comunicativos, motivados por la informatización social. Por eso durante los años 1996 y 1997, realizo una estancia como investigador del GRICIS-UQAM (Groupe de Recherche sur les Industries Culturelles et l'Informatisation Social de la Universidad de Quebec a Montreal, Canadá), con el profesor Gaetan Tremblay, director del GRICIS, y que por entonces era uno de los investigadores clave de las NTIC y sus repercusiones sociales (TREMBLAY, 1995).

La estancia investigadora iba destinada a seleccionar los "Parámetros para el análisis de los procesos de informatización social en España". No obstante, conforme los iba reuniendo derivaba, cada vez más, también, hacia otro tipo de observaciones casuales que no me servían como parámetros, pero sí para la construcción de una metodología de investigación audiovisual (aplicada) y de un paradigma científico del audiovisual (LORITE GARCÍA, 2015). Voy realizando, por tanto, este doble trabajo investigador consistente en diseñar un marco racional de parámetros destinados a evaluar cuantitativa 
y cualitativamente los procesos de informatización social y en sumergirme en una especie de caos o de espiral casi infinita del conocimiento desde la que me voy preguntando qué se transforma y qué no se transforma de las sociedades informatizadas y conectadas a la red de redes como Internet, qué es lo que cambia realmente de los hábitos, costumbres y maneras de relacionarse de los ciudadanos y qué se modifica de sus entornos urbanos, domésticos, educativos $\mathrm{y}$ de ocio con las NTIC.

Nada más llegar a Montreal me doy cuenta, durante la primera fase destinada a la lectura y documentación de artículos, libros, informes, ponencias, etc. que tanto lo que leía como lo que iba observando (con mi mirada física y mediatizada por el lenguaje visual a la vez), anotando en mi cuaderno de notas, fotografiando con mi cámara, así como los diferentes materiales gráficos, audio $\mathrm{y} / \mathrm{o}$ visuales que iba reuniendo desde mis rutinas cotidianas, desde mensajes que me llegaban principalmente desde los medios de comunicación tradicionales (periódicos, televisiones, cines, publicidad), me transmitían continuamente un mismo titular o eslogan: la sociedad se está transformando gracias a las NTIC. Era fácil de constatar que no cesaban de darse nuevas transformaciones sociales con los nuevos avances tecnológicos, principalmente informáticos, pero ¿qué se estaba transformando realmente y qué no se estaba transformando? ¿cómo podía capturar dichas transformaciones socio-mediáticas? Y sobre todo ¿cómo podía captar la realidad social y mediática, con sus sonidos propios, sus imágenes fijas y en movimiento, desde la misma transformación y hacerlo desde mi mirada, mediatizada por la de la cámara?

Empecé a responder a estas y otras preguntas redactando una serie de discursos textuales, en los que recogía los primeros indicios para una metodología de investigación audiovisual (aplicada) desde la mirada de la cámara, que titulo: "À la poursuite des molecules. Quelques idées de recherche sur les transformations socio-médiatiques" (Atrapar las moléculas del aire en movimiento. Algunas ideas para investigar las transformaciones socio-mediáticas) (LORITEGARCÍA; TREMBLAY, 1997). Posteriormente lo amplio y matizo con nuevos textos para ser presentados en congresos, debatirlos en cursos y seminarios universitarios y difundirlos en algunas publicaciones (LORITE GARCÍA, 1999, 2000, 2002b, 2004).

\section{LA CONSIGNA}

Un primer concepto que acuñé para estudiar las transformaciones socio-mediáticas desde el tren de las transformaciones, fue el de consigna (LORITE-GARCÍA, 1999, 2000, 2002a). Cuando se me ocurrió el término pensé que acabaría encontrando uno más apropiado, pero sigo sin dar con uno mejor, uno que suene más científico y suscite mayor credibilidad entre la comunidad científica, aunque estoy consciente que la credibilidad científica es relativa. Tampoco sé por qué pensé que necesitaba una consigna para investigar las transformaciones socio-mediáticas si se trata de una palabra que se usa principalmente para dar ciertas órdenes militares de manera jerárquica entre la tropa o difundir arengas políticas a modo de proclamas unitarias entre los militantes de los partidos políticos. No pretendía ni una cosa ni la otra, aunque si coincidía en algo con estas tomas de decisiones estratégicas. La consigna es un reclamo, una especie de eslogan, de frase llamativa e impactante, de fácil recuerdo, que sirve de guía y permite no perderse, o perderse lo menos posible, en el complejo e incluso casi utópico intento de atrapar al vuelo algo que se transformaba constantemente y de manera tan sumamente acelerada como son las tecnologías de la información y comunicación, conectadas en red, con sus usos e interacciones sociales, y de saberlo explicar, otorgándole el mismo sentido, de diferentes maneras textuales, gráficas y audiovisuales. Decidí 
"atrapar moléculas del aire en movimiento" (esta era la consigna) porque no quería quedarme tan sólo en recoger muestras de datos de un momento estanco, como suele hacerse habitualmente con muchas investigaciones cuantitativas y cualitativas y como habría diseñado mis parámetros para el análisis de la informatización en España. Me interesaba conocer y mostrar la transformación desde la transformación. De poco sirven las referencias de un momento espacio-temporal si no cesan de cambiar continuamente las referencias que tomamos de él. Como mínimo hay que tener referencias de varios momentos y utilizar parámetros o indicadores que puedan medir adecuadamente el cambio. Dicho seguimiento periódico puede ayudarnos a hacer un seguimiento sobre usuarios de Internet y modalidades de usos. Son datos que permiten evaluar las tendencias cuantitativas, pero no permite recoger lo que va produciendo el cambio desde el mismo cambio.

Como el concepto de consigna va destinado a una epistemología, teoría y metodología para el estudio audiovisual de la mediatización de la realidad social desde el tren de las transformaciones socio-mediáticas hay que plasmarlo de la forma visual que muestro a continuación además de la manera textual que he intentado sintetizar anteriormente. Se trata de un concepto que, al reproducirlo en un papel rectangular, bidimensional, como éste, permite adquirir una perspectiva gráfico-textual polisémica. La consigna la pienso y la plasmo por primera vez en el texto del GRICIS (LORITE-GARCÍA; TREMBLAY, 1997) de la siguiente manera (la redacción original es en francés):

Figura 1 - Representación bidimensional y gráfico-textual de la consigna

\begin{tabular}{|} 
Atrapar las moleculas del aire en movimiento (roman) \\
Atrapar las moléculas del aire en movimiento (courier) \\
Atrapar las moléculas delaire en movimiento (monotype cursiva)
\end{tabular}

Dichas fuentes tipográficas venían con la versión Microsoft Word 6.0 (era la que usaban los ordenadores de mediados de los 90). Este software de procesamiento de textos dispone de los mismos tipos de letras veinte años después con las nuevas versiones (¿transformaciones? ¿qué transformaciones?). No me gusta argumentar por qué presento la consigna de esta manera gráfico-textual. Intento que lo expuesto suscite en el lector la decodificación que considere oportuna. Va destinado a ampliar el conocimiento. No obstante, al comprobar lo abstracta que resultaba dicha definición gráfica al ser expuesta y debatida en varios cursos, seminarios y congresos tomé la decisión de explicar por escrito mi interpretación, aunque sin el afán de dejar de lado las nuevas interpretaciones que podía seguir suscitando. La reproducción de la consigna de esta manera gráfica pretende incorporar al proceso investigador la diversidad expositiva e interpretativa del discurso visual, aunque se trata de una frase textual. Cada tipología de letra detenta un nombre que se asocia, a su vez, con un uso, asociado generalmente con ciertos patrones contextuales, históricos y culturales. Los diferentes signos tipográficos detentan distintos sentidos de codificación y de decodificación sociocultural. Exponer varios tipos de letras con la misma frase pretende advertir que es necesario transmitir el conocimiento desde su lectura e interpretación plural. No es lo mismo escribir únicamente la frase con la letra Times New Roman, tamaño 12 (¿por qué esta letra?), que suelen pedir para redactar bastantes artículos y comunicaciones, que utilizar varias tipografías en el mismo texto. Dicha (re)presentación ganaría sentido polisémico si también se pudiera reproducir en diferentes tamaños de letra. De momento no he querido usar esta posibilidad gráfica. Todas las frases están redactadas con el mismo tamaño 12 de letra. 
Una imagen o soporte fotográfico que permite ampliar los registros textuales y gráficos de la función investigadora audiovisual de la consigna es la que podemos ver a continuación (Figura 2).

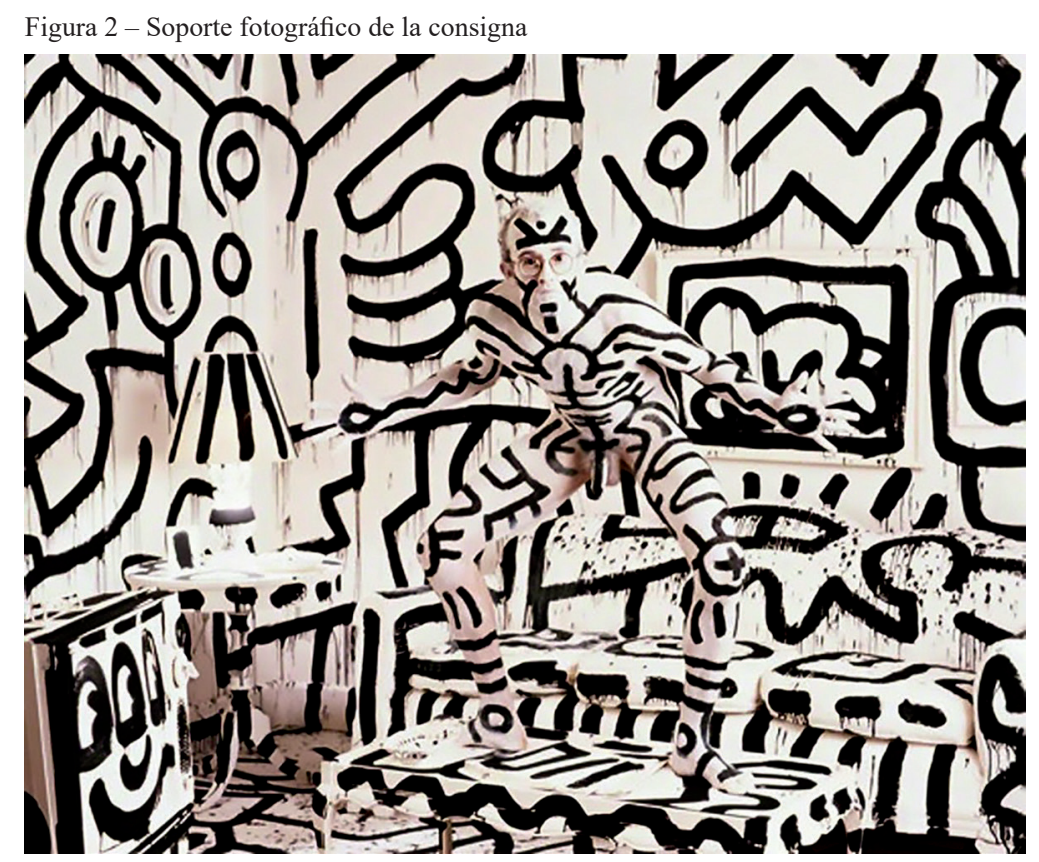

Fuente: Keith Allen Haring. Foto de Annie Leibovitz (James Danziger Gallery, New York City, 1986).

Se trata de una fotografía realizada por Annie Leibovitz (1986) para la exposición en la James Danziger Gallery de Nueva York, celebrada en el año 1986, en la que muestra al artista y activista social Keith Allen Haring (nacido el 4 de mayo de 1958 y fallecido el 16 de febrero de 1990) con los mismos trazos que la pared y el mobiliario. Se atrapan las moléculas del aire en movimiento o las transformaciones socio-mediáticas desde su transformación, si distinguimos la forma humana con movimiento, del fondo material estático de apariencia similar. Hemos de aprehender lo que se mueve y no confundirlo con lo inerte, lo que puede cambiar de lugar y lo que no. Distinguir el tren de la estación.

La consigna no es un objetivo en sí, ni una hipótesis, ni una herramienta metodológica, ni el objeto de estudio, es en todo caso el alma o especie de guía espiritual, principalmente heurística, de la investigación audiovisual, aplicada en este caso a las TSM. El profesor de lenguaje radiofónico, Ricardo Haye (1995), alumno del curso "Investigar las transformaciones socio-mediáticas" que impartí en el doctorado de Comunicación Audiovisual y Publicidad de la UAB, los años 1987-88, la definió como "la formulación poética del objeto de estudio", aunque también matizó que se podría tratar de "un sofisma mesiánico". A estas ideas iba agregando otras como las que recojo al exponérselo a Gaetan Tremblay en el momento de intentar argumentarle de manera verbal tan solo, sin soporte gráfico ni fotográfico, lo que pretendo con la consigna (LORITE-GARCÍA; TREMBLAY, 1997, p. 7-9):

- “La consigna? pero ¿qué es la consigna?”, exclama el profesor Gaëtan Tremblay, tras mostrarle un caótico esquema que he improvisado en la pared del despacho con postis a modo de storyboard.

- “¿Conoces la religión, no?”, le insinúo para intentar explicárselo con un ejemplo, aunque no entiendo porque me acude la religión a la mente, en este momento.

- "Si, claro", responde asintiendo con la cabeza y la mirada. 
- "La consigna es como Dios y la investigación como Jesucristo. El primero es intangible, invisible, pero sirve como referencia espiritual para muchas iglesias, sectas y religiones, el segundo dicen que es su encarnación en la tierra, es la práctica, es su..."

- “Entonces la consigna es el hilo conductor de la investigación?”, interrumpe el profesor Tremblay.

- No porque el hilo conductor es el método que a su vez se diferencia del objeto de estudio, de la hipótesis central y sub-hipótesis, de la metodología, de la teoría, de los trabajos de campo,...."

- "En Norteamérica la metodología incluye las técnicas de estudio y la consigna equivale a la hipótesis central"

- "Es que la consigna más que la hipótesis principal es como una guía espiritual, filosófica, que inspira toda la investigación. No es tampoco el objetivo principal porque éste consiste en el diseño de una metodología y una teoría para intentar atrapar las moléculas del aire en movimiento o las continuas transformaciones socio-mediáticas..."

\section{- "No entiendo"}

- "A ver, otro ejemplo, la consigna es como esa cita de algún autor consagrado que recogen muchos libros en la primera página, que no tiene nada que ver con la obra pero que parece inspirarla"

- "Bien...."

- "Bueno, creo que aún está todo un poco verde, tal vez lo pueda concretar un poco más para el próximo encuentro" le digo al profesor Tremblay mientras noto que me faltan muchas moléculas del aire para respirar, al margen de las que me quedan por atrapar de las transformaciones socio-mediáticas.

El concepto de consigna se iba ampliando más que condensando al ser expuesto y debatido. Me sentía satisfecho porque estaba cumpliendo su misión epistemológica. Esta especie de provocación permitía abrir al máximo el debate sobre la necesidad de un pensamiento propio, destinado a desarrollar un método científico de investigación audiovisual, y poderlo aplicar en las diferentes líneas de investigación que iba desarrollando sobre análisis de medios de comunicación e información y su impacto social. Sin embargo, debía andar con suma precaución al hacer este tipo de giros desde la Academia. En más de una ocasión tuve que repetir y aún hoy sigo reiterando al escribir textos como éste que si me atrevo a difundir juegos gnoseológicos como éstos es porque he estudiado y sigo estudiando, experimentado y sigo experimentando, defendía y sigo defendiendo que la investigación audiovisual de la sociedad ha de saber conjugar las propuestas científicas universales, ampliamente contrastadas, con las experimentales. Sigo defendiendo el método científico, pero también voy comprendiendo sus limitaciones y sobre todo sigo haciendo giros epistemológicos para incorporar lo audiovisual como científico en la Academia. Todo lo que se hace y muestra con la cámara sigue siendo considerado un complemento o adorno expositivo al servicio de lo que recogemos de manera oral y lo sintetizamos por escrito. Paradójicamente el texto sigue siendo el rey de la Academia, lo audiovisual el súbdito en la época del audiovisual.

No me dedico a escribir la frase "atrapar las moléculas del aire en movimiento" en diferentes tipologías gráficas como si se tratara de una obra pictórica abstracta y yo el pintor que manifiesta haberla hecho sin otorgarle un sentido concreto a su obra. Para adoptar esta determinación me nutrí de obras 
que invitan a (re)pensar las (re)presentaciones visuales de la realidad y las (re) construcciones de los imaginarios colectivos, de autores clásicos que a lo largo de su carrera declinaron por acudir a otra conexión con lo visual, como abstracta pero heurística a la vez, y se permitieron transmitir su pensamiento desde más allá de la gramática textual, aunque reducido al rectángulo bidimensional del formato libro. Para tomar esta decisión me marca bastante el ensayo de Foucault (1981) sobre dos dibujos de Magritte Ceci n'est pas une pipe, que tuve la oportunidad de conocer y debatir durante los años 80 en las clases de sociología del conocimiento y que desde entonces lo venía usando como libro de cabecera porque tenía esa extraña sensación de que tarde o temprano acabaría utilizándolo para algo más.

Figura 3 - La consigna se nutre de Magritte y Foucault
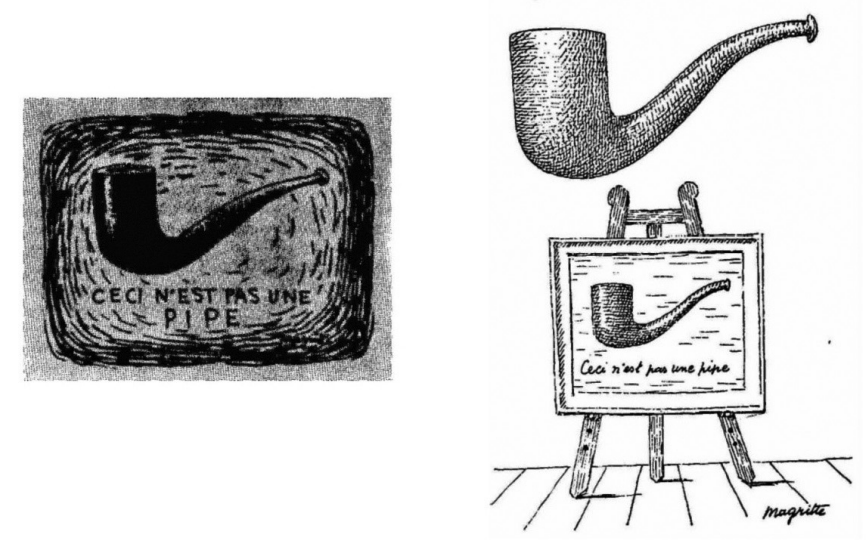

Fuente: Foucault (1981: 32)

Con operaciones tan simples como éstas Foucault considera que Magritte deshace la tradición milenaria del caligrama de tener que mostrar y nombrar lo mismo. Foucault se pregunta al analizar las dos imágenes anteriores:

¿quién me puede decir seriamente que ese conjunto de trazos entrecruzados, encima del texto es una pipa? ¿O acaso hay que decir: Dios mío, qué estúpido y simple es todo esto; ese enunciado es perfectamente verdadero, puesto que es evidente que el dibujo que representa una pipa es una pipa? (FOUCAULT, 1981, p. 32)

Para comprender mejor la consigna también acudí a las enseñanzas de obras como Message et Massage de McLuhan y Fiore (1968), que de manera casual (la observación casual que no es casual observación o la casualidad que no es causalidad) encontré en una librería de segunda mano de Montreal. El autor de textos fundamentales como Understanding media: the extensions of man (MCLUHAN, 1964), y The Gutenberg Galaxy: the making of typographic man (MCLUHAN, 1962) produce con el artista gráfico Quentin Fiore una

expérience visuelle et litteraire unique, pour explorer, analyser, et expliquer notre nouvel univers, avec autant de pénétration que d'humor. Pour la premier fois, un "penseur" explique ses théories d'une façon vivante, actuelle, en utilisant à la fois l'écriture et les graphiques. Des ont, des dessins, des recherches typogrhafiques éclairent le texte, ont en réalité partie du texte, et sont la preuve même du "message" de McLuhan. (MCLUHAN; FIORE, 1968, p. 1)

Es evidente que la frase de McLuhan: "La nouvelle interdependance électrónique recrée le monde à l'image d'un villaje global" (MCLUHAN; FIORE, 1968, p. 66-67) sobredimensiona su significado si la acompañamos de la foto de un poblado como el que se muestra a continuación: 


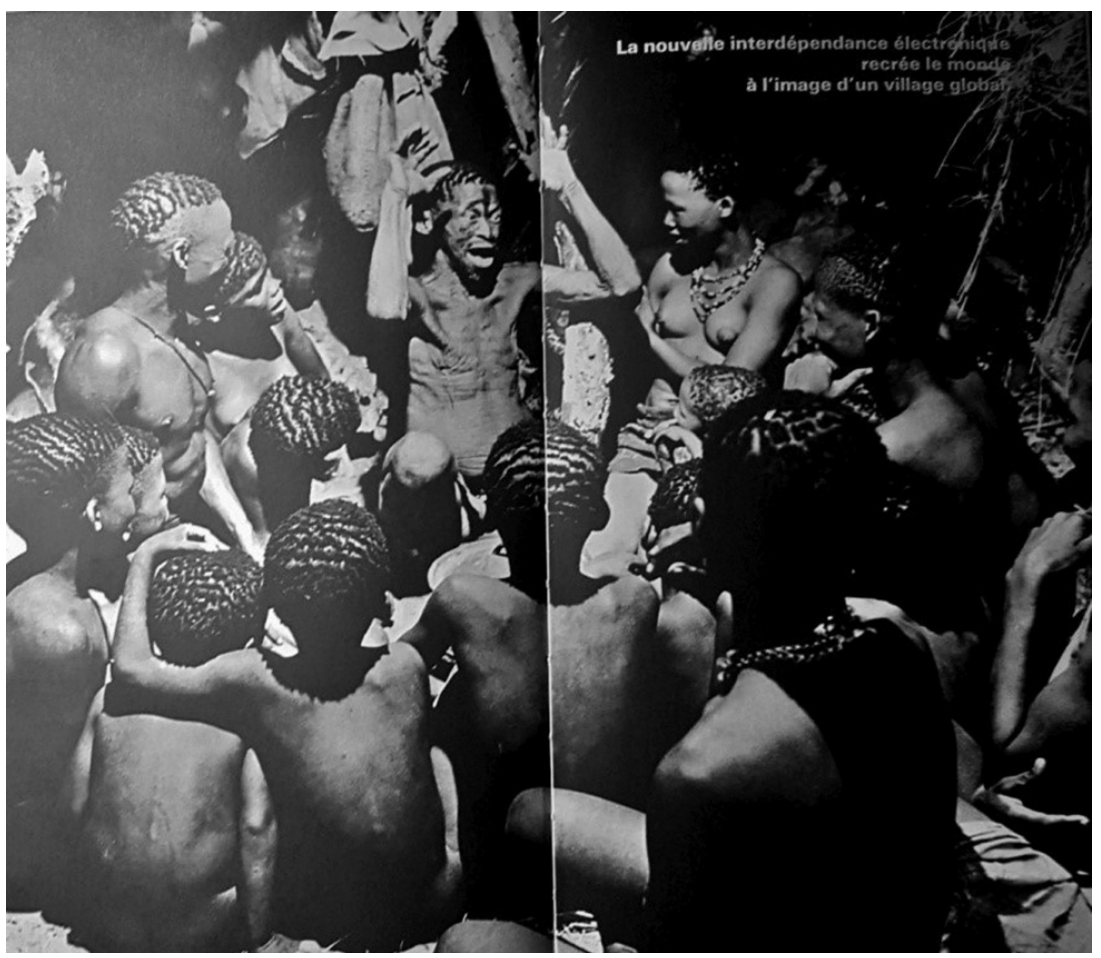

Fuente: McLuhan y Fiore (1968, p. 66-67).

\section{LA OBSERVACIÓN CASUAL QUE NO ES LA CASUAL OBSERVACIÓN}

A la misma vez que voy pensando y exponiendo los indicios epistemológicos y teóricos, sin olvidar los metafóricos, gráficos, fotográficos y heurísticos, desde los diversos registros gráfico-textuales mostrados anteriormente, desarrollo una metodología para investigar las transformaciones socio-mediáticas desde el tren de las transformaciones y no desde la estación, que permita captar los movimientos del hombre de la foto de Leibovitz y no fijar la mirada únicamente en la pared.

La denomino observación casual (LORITE-GARCÍA, 2000) porque consiste en seleccionar desde mi cotidianidad los diferentes impactos visuales que voy captando con mi mirada, bastante mediatizada por la óptica de la cámara, para conocer las transformaciones socio-mediáticas desde su misma transformación, en determinados contextos urbanos. La pongo en práctica en primer lugar en Montreal, durante los años 1996 y 1997, y posteriormente en otras ciudades por las que transcurro por cuestiones laborales (investigación y docencia universitaria) como México D.F. y Porto Alegre, y asimismo desde mi cotidianidad en la metrópolis de Barcelona (no sólo la ciudad sino el área metropolitana o periferia).

Es observación casual porque la ejecuto al azar desde los diferentes lugares por los que transcurro cotidianamente desde mis rutinas diarias. El viaje en metro, el desayuno en una cafetería o la comida en el restaurante, que suelo frecuentar a menudo, da para recoger instantáneas visuales de esta realidad y comprobar con nuevas observaciones casuales, lo que llega a transformarse realmente de espacios con la penetración acelerada de las nuevas tecnologías de la información y la comunicación con sus redes y convergencias mediáticas. Como es casual no selecciono previamente los puntos 
de observación ni el tiempo que dura dicha observación como suele hacerse desde la observación distante y participante. Las diferentes observaciones de Montreal las voy anotando en mi cuaderno y las reúno en un total de dieciséis discursos. El discurso que denomino "realidad virtual" es un ejemplo de cómo lo redacto desde esa doble manera de mirar, la física mía y la mediatizada por la cámara (LORITE-GARCÍA; TREMBLAY, 1997, p. 21-24): "Siete de abril de 1997. Diez y media de la mañana. El profesor Pierre Levy $(1994,1995)$ de la Universidad Paris-VIII, pronuncia una conferencia sobre Virtualité et intelligence collective dans la ville, en el marco de las Jornadas Penser le Virtuel. El profesor sostiene un discurso muy positivo de lo virtual. En concreto, el del mundo virtual de Internet como ágora o plaza pública ideal para el desarrollo de la sociedad democrática global, criterio que ha sido estudiado por otros autores como Postman (1993), Bell (1981), Echevarría (1994) y Negroponte (1995) desde otras perspectivas. Hasta el mismísimo Bill Gates lo define de manera muy clara en su libro Camino al futuro (1995): ágora $=$ microsoft (por cierto, este programa informático tiene una definición simple, en la línea gatesista, sobre analógico y digital. Si se quiere ver la hora en modo analógico el programa te instala un reloj con agujas, si se desea ver en modo digital aparecen horas y minutos en números, simple, ¿verdad?). El profesor Levy lleva a cabo una disertación muy bien orquestada sobre lo virtual en la salle Marie-Guérin-Lajoie de la UQAM, aula magna clásica enorme. La sala está medio llena o medio vacía según la ideología con la que se quiera interpretar el encuentro. El profesor lee e interpreta su conferencia, sentado en medio de una mesa alargada, instalada en el centro de un escenario enorme, con las dimensiones propicias para representar, sin lugar a duda, las mejores óperas clásicas de Verdi y Wagner. La única decoración de semejante escenario faraónico es una pantalla de aproximadamente $3 \times 4$ metros, situada al fondo a la izquierda, detrás del profesor, en la que se van proyectando algunos diseños. Llama la atención uno que muestra una especie de radiografía del cerebro humano. Mientras se escucha a Pierre Levy con su discurso sobre lo virtual y se ve dicha imagen al fondo, se construyen múltiples asociaciones semióticas. Unas son informativas. Nos hacen ver que el encuentro se celebra para pensar lo virtual. Otras son deformativas porque indican que lo virtual es cerebral y eso ya es más discutible. Tras el discurso del profesor Levy se abre el turno habitual y tradicional de preguntas. Algunas personas, la mayoría profesores/ as, toman la palabra de una en una. Se le dirigen desde un micrófono instalado en el palco de butacas (conferenciante emisor arriba, asistentes receptores abajo). Casi todas las intervenciones empiezan elogiando la prolija obra del profesor, y añaden alguna pregunta a la que Levy responde emplazando, directa $o$ indirectamente, a una relectura de su obra escrita. Se trata del tradicional pez que se muerde la cola habitual de este tipo de encuentros analógicos, anacrónicos, tradicionales y propios, en definitiva de la oratoria milenaria occidental. Una azafata joven y estilizada, vestida para la ocasión con el correspondiente uniforme color naranja, pañuelo de cuello y zapatos de tacón (¿azafatas y uniformes analógicos?), toma, a la salida, el nombre y la dirección de los asistentes para remitirles por correo tradicional un CD-ROM con los materiales de las jornadas. En este mismo lugar pueden adquirirse los libros del profesor Levy (ver bibliografía) en formato analógico y no digital y a precios un tanto astronómicos, que es como decir que el pensamiento virtual se traduce a un elevado coste monetario real. En la puerta, un grupo de estudiantes reparten panfletos de Le Club de Marketing de la UQAM, invitando a la "Party de FinSession": "mettant en vedette le: Boogie Wonder Band, 10 musiciens-chanteurs sur scène qui nous ramèront dans le temps en interprétant les meilleurs succès disco des années 70". Días atrás, en concreto el 4 de abril, L'association des étudiants asiatiques de la UQAM organizaron el desfile de moda 1997: "Le show le plus HOT de l'année 97", con la ayuda de las empresas de cerveza Molson Dry y Corona Extrael, el restaurante La Porte d'Asie y Deuce Wild Productions. Reflexión: Al mediodía todos los conferenciantes y asistentes a las jornadas virtuales efectúan el almuerzo de rigor. El estómago es una de las 
pistas principales o punto de observación fundamental de las transformaciones socio-mediáticas, también lo son las fiestas de fin de curso que organizan los universitarios de la era Internet con música retro de los setenta y los desfiles hots de moda de las estudiantes universitarias asiáticas, e incluso la misma moda" (LORITE-GARCÍA; TREMBLEY, 1997, p. 25-28).

Un medio de transporte como el metro de una de las metrópolis más grandes del mundo como era México DF en el año 1999, se convierte, durante mi estancia como profesor del TEC de Monterrey, en un punto perfecto para llevar a cabo mis observaciones casuales sobre las transformaciones socio-mediáticas o convivencias digitales y analógicas como venía denominándolas también. Compruebo que al usar cotidianamente este medio de transporte como un ciudadano más y por motivos laborales (voy a dar mis clases a la universidad) voy reuniendo diferentes indicios desde mi mirada, mediatizada por la mirada de la cámara, sobre las transformaciones socio-mediáticas desde la transformación. Se trata de una observación casual porque el tiempo que destino a la observación, así como a la selección del lugar no lo establezco previamente. La duración de la observación guarda relación con la del viaje diario de ida y vuelta en metro a mi trabajo y la llevo a cabo tantas veces como me sea posible durante mi estancia como profesor en el DF.

Dichas observaciones casuales permiten redactar nuevos discursos textuales, similares a los de Montreal, que en realidad son narraciones que construyo y redacto a partir de lo que voy captando con mi mirada (física y mediatizada por el lenguaje de la cámara). Le agrego los diferentes materiales que voy encontrando a mi paso por la ciudad desde mi casa a la universidad. Por ejemplo, la publicidad que a veces te entregan en la entrada del metro. Con todo ello acabo editando el discurso textual que reproduzco a continuación, texto que estructuro de la misma manera con que realizaría cualquier producto o discurso audiovisual. Narro la vida cotidiana como si fuera el guión de una película. Cada párrafo es como una secuencia con diferentes planos y escenas. Pero en cada frase incluyo, además, una serie de referencias (sociológicas, comunicológicas y antropológicas), o cortes visuales, ejecutados con la mirada, secuencias de contrastes visuales, mediante una edición similar a la teoría del montaje cinematográfico, para mostrar lo que de manera efectiva se transforma o puede tenerse en cuenta para ser observado en el futuro como referencia de la transformación, y lo que no.

Por entonces opto por este tipo de discurso textual, mediatizado por el lenguaje visual, porque era la única manera posible de mostrar dicha realidad. No resultaba posible usar la cámara fotográfica para retratar cierta cotidianidad social. Podría resultar peligroso fotografiar a los pasajeros del metro del DF. Además, las cámaras fotográficas usaban carretes y había que pensarse muy bien la toma y las de video no se solían usar desde el día a día. Lógicamente van cambiando mis observaciones visuales casuales con la llegada de los nuevos teléfonos móviles con cámaras de calidad como una de las prestaciones principales. Ya es posible retratar a los viajeros del metro con bastante precisión sin que lo noten (aunque hay que pensarse el uso ético que hacemos de estas imágenes). La cámara del móvil es el complemento perfecto de la mirada para observar de manera casual y audiovisual la transformación social y producir discursos audiovisuales, sin necesidad de reducirlos a los textuales como el que recojo en el texto siguiente: "Un viaje diario de ida y vuelta en la línea de metro que va desde el Zócalo o centro de la ciudad hasta el campus universitario del TEC situado en el sur del Distrito Federal, permite ir articulando, paulatinamente, un rico y singular discurso visual y mental, a la vez, de esta realidad socio-mediática local, cercana, perteneciente a un mundo global. Mientras leemos a diario en nuestro periódico bastantes noticias y publicidad sobre los continuos avances tecnológicos de la industria informática, podemos contemplar en el exterior del vagón múltiples pistas de 
una sociedad que no cambia a la misma velocidad o que cambia muy poco o nada. Por ejemplo, allá sigue día a día el mismo circo permanente de siempre y el Centro de Neuróticos Anónimos (con un índice cada vez mayor de clientes, según puede leerse en la misma sección de sociedad que suele incluir todo lo relativo a los avances informáticos, casual coincidencia informativa que me permite recordar lo útiles que son las noticias publicadas en los periódicos y su asociación para profundizar en el estudio de la sociedad haciendo uso del discurso intertextual). Allá sigue inamovible la pastelería en la que se venden "tortas locas", también el negocio de funerales, el restaurante chino La Gran Muralla, y el taller en el que se reparan todo tipo de relojes (los viejos de dos agujas, analógicos, y los nuevos con dígitos simplemente, digitales; para entender mejor esta diferencia entre analógico y digital siempre he recomendado leer los conceptos prácticos que aplican en Microsoft para poner en hora el reloj del ordenador). También permanece la maderería, la neverería, la hojalatería, la tintorería, la planchaduría, el centro de engargolados, la tlapalería y la ferretería, una notaría llamada 69 (¿por ser un año después al 68?), el establecimiento de la cadena de Farmacias Similares que venden "lo mismo pero más barato" (¿lo mismo de qué y de quién?), una tienda de uniformes militares y otra de transmisiones automáticas para vehículos de todo tipo llamada Espartaco (¿por qué Espartaco?). También pueden verse algunas informaciones temporales como la de una valla publicitaria de una agencia de viajes que anuncia un recorrido muy barato por los "Estados Unidos, de punta a punta" (¿para quién?) junto a otra de una exposición reciente de los Mayas (¿para quién?). Semejantes asociaciones me permiten fijarme, a partir de este momento, en algunas asociaciones lingüísticas multiculturales. Observo que hay un kitchen market, un Wal Mark (un texto adaptado al mejicano, probablemente, de los Wall Mart estadounidenses) con "lo mejor de lo mejor en televisión", el centro de estética yes, un Auto-Mac y una academia que imparte un curso rápido de diseño de páginas de Internet junto a un centro de depilación definitiva por ultrasonido. Mientras el exterior me ofrece semejante cúmulo de pistas simples y compuestas voy recogiendo cotidianamente otras observaciones en el interior del vagón que me ayudan a precisar el más complejo de los análisis multivariables y socio-comunicativos experimentales en mi cabeza. Dos ciegos piden unos pesos para comer, uno con un órgano Yamaha (los japoneses) colgado al hombro y otro con una guitarra un tanto vieja (los españoles). Cuando se bajan los dos mendigos sube otra pareja de jóvenes que pide unos pesos para la lucha contra el Sida, uno de ellos lleva colgada una mochila Nike (los americanos). Después entra un acordeonista ciego y a éste le sigue una vendedora de "goma de mascar sin azúcar, a dos pesos, para la garganta reseca de ese profesor que tiene que hablar todo el día". Conviene recordar que al tiempo que se encadena a diario semejante "comercio humano", claro efecto de las políticas económica y social mejicana, según me explican personas de distintas ideologías cuando se le pregunta un por qué al respecto, continúo leyendo noticias con los últimos avances de las nuevas tecnologías de la comunicación/información. Si una de esas jornadas desvío la mirada hacia otros lugares del interior del vagón como pueden ser las paredes internas, puedo añadir nuevas pistas transitorias sobre convivencias digitales y analógicas y transformaciones reales de esta sociedad local. Durante semanas puedo observar, por ejemplo, un cartel anunciador del 'Primer Festival de Ajedrez: Zócalo Capitalino, magno maratón popular, récord mundial de participantes, evento que permite a los internautas encontrar más datos en una página de Internet diseñada a propósito e interactuar con la organización, haciendo uso de un e-mail" (LORITE-GARCÍA, 2000, p. 6-8).

\section{¿ATRAPAMOS LAS MOLÉCULAS?}

Las moléculas nunca acaban de atraparse del todo. Podemos afirmar que se viaja con ellas al intentar capturarlas de manera casual. Mientras viajamos 
en el tren de las transformaciones socio-mediáticas, aplicando la observación casual (que no es casual observación) captamos indicios de la realidad desde una mirada física e instruida, a la vez, para mirar desde la óptica de la cámara, que nos permite comprender la transformación desde la transformación y explicarla de manera textual y audiovisual.

De hecho, ya había atrapado algunas moléculas y viajaba con ellas desde mis primeras observaciones casuales en Montreal. Basta con leer las conclusiones de aquel primer intento de acercamiento a las transformaciones socio-mediáticas, durante los años 1996 y 1997, para comprobar las moléculas que ya había atrapado por entonces: “... el acceso cada vez mayor a Internet, facilitado por unas tarifas rebajadas casi a diario por las compañías de telecomunicaciones, y una publicidad impactante presente en todos los medios tradicionales, conjugado con una oferta cada vez más amplia de informaciones y comunicaciones en las redes, circulando a velocidades supersónicas, no están modificando ciertos hábitos de los montrealenses, practicados desde antes del nacimiento de estos nuevos sistemas comunicativos e informativos. Por ejemplo, siguen utilizando la bicicleta (es un bien muy preciado desde hace muchos años), beben una buena cerveza de cosecha propia de 5 a 7 de la tarde (es otro bien histórico muy preciado) y se revuelcan por la hierba de los parques mientras lanzan cacahuetes a las ardillas (es un auténtico placer ancestral). En cualquier caso, sospecharíamos de ciertos impactos sociales de los nuevos medios, negativos y/o positivos en función del posicionamiento ideológico personal, si cerrasen los comercios de bicicletas, los pubs, los cines, los museos, las lencerías, los gimnasios, el despacho del correo tradicional, los todo a 1 dólar y los parques públicos. Pensaríamos que algo extraño está ocurriendo, si desaparecen los medios tradicionales (prensa escrita, cine, televisión, radio, y publicidad) con sus lenguajes, contenidos, programaciones, rutinas de producción y su consumo diario, de signo muy gratificante para las audiencias. Algo raro estaría pasando, además, en este centro urbano neurálgico del planeta, si se extinguen o cambian de manera radical, ciertas buenas costumbres y tradiciones habituales. Por ejemplo, si se dejasen de celebrar los festivales mundiales del humor, de la cerveza, de fuegos artificiales, de jazz, de cine, etc.; si desapareciesen las fiestas de fin de curso de los/las estudiantes universitarios/as, si cambian las tradiciones milenarias occidentales de transmisión universal y unidireccional del conocimiento científico (incluso para disertar sobre lo virtual); si las costumbres alimenticias se adaptan a la velocidad que circula la comunicación por las autopistas y el estómago solicita injerir comida a cada millonésima de segundo; si mueren las tradiciones milenarias sectarias y religiosas, presentes en todas partes (como siempre y como Dios), y si se arruina el prehistórico negocio del comercio sexual. Habría que sospechar, tal vez, de los efectos (positivos y/o negativos) de los nuevos medios, fabulemos e ironicemos un poco, si Jojo medium y madamme Rioux cuelgan los hábitos esotéricos y las peels girls o danseuses nues simplemente se visten y todas ellas deciden ganarse la vida limpiando las oficinas de la Place Dupuis. De todas formas, faltaría saber si dicho cambio de roles profesionales es una consecuencia inmediata del impacto de los nuevos medios o bien obedece a la aplicación de las políticas neoliberales de Bienestar Social. Una pista importante obtendríamos al observar el pelotón de mendigos de la rue Sainte-Catherine. Bastaría con comprobar si continúan pidiendo "change pour manger, s'il vous plaît, monsieur" o prefieren ordenadores, aunque sean obsoletos, para teletrabajar en Internet. Lo que se observa en realidad, volvamos a la seriedad, es que estas rutinas cotidianas del centro urbano de Montreal conviven con las nuevas comunicaciones digitales. El calendario tradicional camina de la mano del tiempo virtual. La sociedad tradicional usa Internet y mira la televisión de siempre desde el sofá. El mundo virtual no está desplazando al analógico. Habrá que ver durante cuánto tiempo. Hay que seguir observando las nuevas convivencias digitalógicas" (LORITE-GARCÍA, 2000, p. 7-9). 
En el año 2013 viajé de nuevo a Montreal por trabajo, 16 años después, y pude constatar, desde una nueva observación casual, que podría escribir un texto muy similar al de 1997. Nada de lo sintetizado en el discurso anterior había cambiado. Continuaban los mismos medios de comunicación tradicionales (prensa, radio, televisión y cine) con sus mismas dinámicas de difusión, emisión y recepción, y sus mismos lenguajes escritos, informativos y audio y/o visuales. Permanecían los mismos parques, las mismas calles con las mismas aceras, las mismas tiendas de ropa (con nuevas modas) e informática (con nuevos modelos), los mismos bares y los mismos hábitos asociados a estos lugares: pasear, comprar, tomar café y cerveza, comer por placer en ciertos restaurantes, ir a las discotecas y pubs, ir al cine, hacer turismo, visitar museos, ir en bicicleta, etc. Permanecía una misma propuesta estética y ambiental de estos lugares y tampoco habían variado ciertos hábitos cotidianos como los alimenticios con sus respectivas horas habituales para el desayuno, el almuerzo y la cena, los educativos con sus calendarios anuales, los religiosos con sus correspondientes ritos eclesiásticos, y los sexuales con las mismas ofertas de peels girls o danseuses nues. Permanecía la ciudad multicultural con su barrio portugués y sus zonas anglófonas y francófonas, y la ciudad de los solitarios (la mitad de sus habitantes viven solos). ¿Transformaciones? ¿Qué transformaciones? La ventaja de un método como éste es que "espía" los cambios desde una mirada audiovisual que retrata la realidad y permite mostrarlos desprovistos de especulaciones orales y reflexiones filosóficas textuales, aunque se trate de una observación que, durante la época analizada de los años 90, se vio obligada a ser difundida en texto, aunque se tratara de textos estructurados como montajes audiovisuales.

\section{REFERENCIAS}

BELL, Daniel. The microelectronics revolution: the complete guide to the now technology and impaction society. Cambridge, MA: The MIT Press, 1981.

CHALMERS, Alan Francis. ¿Qué es esa cosa llamada ciencia? una valoración de la naturaleza y el estatuto de la ciencia y sus métodos. Madrid: Siglo Veinteuno de España, 1982.

ECHEVARRIA, Javier. Telépolis. Barcelona: Destino, 1994.

FEYERABEND, Paul Karl. Contra el método: esquema de una teoría anarquista del conocimiento. Barcelona: Ariel, 1981.

FOUCAULT, Michel. Esto no es una pipa: ensayo sobre Magritte. Barcelona: Anagrama, 1981.

GATES, Bill. Camino al futuro. Madrid: McGraw-Hill, 1995.

GINZBURG, Carlo. Spie: radici di un paradigma indiziario. In: GARGANI, Aldo (Coord.). La crisi della ragione: nuovi modelli nel rapporto tra sapere $\mathrm{e}$ attività umane. Torino: Giulio Einaudi, 1979. p. 57-106.

92 El queso y los gusanos: el cosmos, según un molinero del siglo XVI. Buenos Aires: El Aleph, 1994.

HAYE, Ricardo. Hacia una nueva radio. Buenos Aires: Paidós, 1995.

IBAÑEZ, Jesús. Nuevos avances de la investigación social: la investigación social de segundo orden. I. $2^{\mathrm{a}}$ edición aumentada. Barcelona: Proyecto A Ediciones, 1998. 
LÉVY, Pierre. L'intelligence collective: pour une anthropologie du cyberspace. Paris: La Découverte, 1994.

. Qu'est-ce que le virtuel? Paris: La Découverte, 1995.

LORITE-GARCÍA, Nicolás. Dinamización social y radio municipal. Barcelona: UAB, 1992.

. Audiencia y televisión global. In: LORITE-GARCÍA, Nicolás; MORAGAS, Miguel (Orgs.). Informes anuales de Fundesco Comunicación Social: tendencias. Madrid: Fundesco, 1993. v. 1, p. 165-175.

. Tolls for the analysis of news media. In: NAPIER UNIVERSITY (Org.). Alliances and alignments: communication in the New Europe. Edinburgh: Napier University, 1996. v. 2, p. 23-34.

. La observación casual: una propuesta para el estudio de las transformaciones sociomediáticas. Santiago de Chile: V Congreso de Alaic, 2000. Comunicación.

Atrapar las moléculas del aire en movimiento: algunas pistas para investigar las transformaciones socio-mediáticas. Barcelona: UAB, 2002a.

. Usos sociales de las NTIC y procesos de dinamización intercultural en Catalunya (España). In: 2001 EFECTOS: GLOBALISMO Y PLURALISMO, 1., 2002, Montreal. Anales... Montreal: GRICIS-UQAM, 2002b. p. 1-14. Disponible en: $<$ https://goo.gl/p8dFZC $>$. Acceso en: 28 nov. 2017.

. La cámara como principal herramienta para la investigación audiovi$\overline{\text { sual de }}$ los procesos de dinamización intercultural mediatizados. Intexto, Porto Alegre, n. 34, p. 178-199, set./dez. 2015.

LORITE-GARCÍA, Nicolás; TREMBLAY, Gaëtan. À la poursuite des molecules: quelques idées de recherche sur les transformations socio-médiatiques. Québec: Université du Québec, 1997.

MCLUHAN, Marshall. The Gutenberg galaxy: the making of typographic man. Toronto: Routledge \& Kegan Paul, 1962.

\section{4.}

Understanding media: the extension of man. New York: McGraw-Hill,

MCLUHAN, Marshall; FIORE, Quentin. Message et massage. New York; Toronto: Random House, 1968.

NEGROPONTE, Nicholas. El mundo digital: un futuro que ya ha llegado. Barcelona: Ediciones B, 1995.

PENSER le virtuel. Université du Québec, Québec, [1994]. Disponible en: $<$ https://goo.gl/MhL4Pr>. Acceso en: 28 nov. 2017.

POSTMAN, Neil. Technopoly: the surrender of culture to technology. New York: Vintage, 1993.

SANTERRE, Lise. La formation des usagers de la micro-informatique domestique: le rôle des consommateurs. Technologies de l'Information et Société, Montreal, v. 2, n. 2, p. 71-88, 1990. 
L'informatisation de la production et le bouleversement des modes de vie: des rapports d'interdépendance. Technologies de l'Information et Société,, Montreal, v. 6, n. 4, p. 337-352, 1994.

TREMBLAY, Gaëtan. The information society: from fordism to gatesism: the 1995 southam lecture. Canadian Journal of Communication, Vancouver, v. 20, n. 4, p. 461-482, abr. 1995. 